\title{
Marketing Thinking Based on the Consumption Structure and Consumption Behavior of two-child Families
}

\author{
Jun Luo ${ }^{1, a}$ and Yulan $\mathrm{Yu}^{2, \mathrm{~b}^{*}}$ \\ ${ }^{1}$ Department of Management, Guangdong University of Science \& Technology, Dongguan 523083, \\ Guangdong, China; \\ ${ }^{2}$ Department of Psychology/ Research Center for Quality of Life and Applied Psychology, \\ Guangdong Medical University, Dongguan 523808, Guangdong, China \\ a luojun003@126.com, ${ }^{b}$ psyyulan@126.com
}

\section{Keywords: Two-child; Consumption structure; Consumption behavior; Marketing strategy}

\begin{abstract}
Universal two-child" policy brings the change of family structure. Households will adjust their consumption structure and consumption behavior according to actual needs. The consumption demand of the second child family will focus on the infant's demand for food, clothing, housing, use and operation. Consumer behavior emphasizes nutrition, quality and safety, and tends to be famous brand goods or imported commodities. At the same time, the diversity, education, entertainment and interest of goods will be paid more attention. The consumption types of households are changing towards the development and enjoyment direction. Facing the new opportunities of the second child policy, businesses need to grasp the psychology of consumers, predict the trend of their development, rethink the positioning of marketing strategy, and formulate the corresponding marketing mix strategy from the aspects of commodity design, product innovation, advertising appeal, brand strategy and price formulation, etc. The purpose of all marketing activities is to benefit children, and satisfying the common desires and needs of children and parents.

In the fifth Plenary Session of the 18th CPC Central Committee, the policy of universal two-child was officially announced. The consumption demand of the second child family will focus on the infant's demand for eating, wearing, living, using and doing. For a family, the income source of the family does not change basically, but the cost of the second child increases, the level of household savings is reduced, and the consumption structure and consumption behavior of the family have changed. Family as a basic unit of social consumption, its consumption structure and consumption behavior are affected by many factors. Such as the level of social productivity development, social and economic system, industrial structure, consumer income level, consumer price and consumption decision-making, the social structure and natural structure of the population, such as the demand structure, consumption psychology and consumption behavior.
\end{abstract}

\section{The Consumption Behavior of a Two-Child Family in a Certain Area of Dongguan}

The change brought by family structure as the main driving force that affects residents' consumption behavior will urge households to adjust their consumption structure according to actual needs. The results of the survey show that the consumption structure of the second family residents in one area of Dongguan was as follows: the proportion of food consumption expenditure to total consumption expenditure was $35.9 \%$, education accounted for $22.1 \%$, housing consumption accounted for $15 \%$, entertainment accounted for $11.2 \%$, insurance accounted for $7.1 \%$, and the other for $8.7 \%$. At present, the demand elasticity of necessities such as clothing, food and housing is relatively low, and consumer spending in this regard is relatively stable. If the family structure is small and the family income is guaranteed, the family's consumption in many aspects will take the initiative to pursue high levels of commodity and service goods, which will lead to a decrease in the proportion of the consumption expenditure for the necessities of life. And the demand for education, entertainment culture, insurance products and so on is more flexible, and will gradually increase, and the type of household consumption will change to the direction of development and enjoyment. However, with the advent of the second child, the family structure has changed. The status of 
children and infants is rising in families, and the proportion of family expenditure on education will increase significantly. As well as the increase of the cost of raising children, children become the main driving force of family consumption. The consumption behavior of two-child families is also changing. The nutrition, quality and safety will be paid more attention before consumption. Firstly, customers will focus on nutrition and safety information such as materials, recipes, modeling and so on. Therefore, consuming behavior tends to brand or imported goods, and safety and quality will be pursued. Secondly, customers pay more attention to the diversification of goods. On the one hand, children's curiosity and playfulness are satisfied. On the other hand, parents hope to improve children's learning cognition and intelligence development ability by contacting different products. Finally, the entertainment and interest of the goods are emphasized. It is biased towards choosing brightly colorful, interesting goods. One of the goals is to attract children's attention and cultivate children's self independence. Family members can take time to do some work or life events. The second goal is to let children focus on one aspect and cultivate children's concentration. The third goal is to enhance children's entertainment and interest and maintain their physical and mental health through easy identification, understanding, favorite patterns or colors.

\section{Marketing strategies of family consumption structure and consumption behavior based on two-child policy}

According to the survey, The proportion of urban children's consumption in the total household expenditure is more than 33\%, which is accounting for $90 \%$ of the total family now. The rapid development of children's consumption and the change of consumption demand bring new opportunities and challenges to the whole industry. In order to make an invincible position in the fierce market competition, enterprises must grasp the characteristics of consumer demand through market research, studying consumer psychology and behavior laws, grasping the psychology of consumers, and predicting the trend of their development and change. Businesses need to re-divide the market of children's consumption market, identify their target markets, and propose suitable market positioning. From the aspects of product innovation, commodity design, advertising appeal and price formulation, the corresponding marketing strategies are formulated.

Product strategy. First, in addition to ensuring the basic utility and basic interests of the consumer, it is necessary to adapt to the changes in consumption and meet the physiological requirements, aesthetic requirements, personality characteristics, and to adapt to the social consumption trend when new products are designed based on the concept of the whole product. This is belong to the core product layer. Children's consumer goods can be eaten, used and worn, which are their basic utility and basic interests. Enterprises can innovate the core concepts of products from the psychological strategies of family members' consumption psychology and consumption behavior to influence or impress consumers. For example, the concept of nutrition or safety of eating is beneficial to improve children's mindfulness, cognition or intelligence. Secondly, Naming, trademark, style and packaging design are also important aspects to stimulate consumers' desire to buy. This is belong to the form product layer. The enterprise should apply the psychological strategy of the name of the goods, such as the use of commodity utility and the borrowing of metaphor, to link the name of the commodity with the characteristics of the commodity, create the brand and stimulate the demand. In the design of color, style, shape and packaging, the psychological characteristics of the children should be taken into consideration, so as to make every effort to be peculiar, lively, interesting, colorful, different in shape, and beautifully packed. For example, children's clothing and toys with children's familiar and favorite cartoon characters, and animal images, often attract children's attention, enhance their degree of love and memory, and meet the consumer psychology of family members. Thirdly, enterprises must carefully study the attributes of commodities, find out the unique characteristics, and extract a product attribute concept that is expected for family members. This is belong to the expected product layer. For example, Hengda ice spring focuses on the "underground drinking water under three thousand meters", which is different from the surface drinking water in the market. Finally, enterprises must provide consumers with more value-added product functions or services. This is belong to the 
extended product layer.

Channel strategy. Enterprises must consider the buying habits of children and their parents, choose and build a convenient channel network to meet the needs of customers, so that consumers can buy suitable products at the appropriate time and appropriate place.

Price strategy. The enterprise needs to understand the demand intensity and the ability to bear the price of this kind of commodity, and implement the demand pricing strategy by studying the consumer's feeling and understanding of the value of the commodity. When entering the market, psychological pricing strategies can be applied appropriately, such as reputation pricing, mantissa pricing, attracting price and other pricing strategies.

Promotion strategy. The commonly used promotional means of enterprises are advertising, personal selling, business promotion and public relations. The successful advertisement must start with the psychological analysis of the consumer in order to find the attraction of the advertisement design in the sense of vision and hearing, and then stimulate the potential purchase desire, thus establishing or changing the attitude of the customer to the enterprise and the product, and affecting the purchase decision. Effective salesmanship requires salesmen to grasp customer psychology, be good at observation and analysis, so as to break through sales barriers, bring customer value and satisfy customers' needs. Business promotion is an effective means to prompt customers to make a purchase decision, such as prizes, free taste, trial and so on. In the application, the methods and strategies of the promotion must be made according to the characteristics of the products and the characteristics of the customers' consumption, so as to achieve the desired results. Public relations is a promotional means that focuses on long-term goals. It promotes sales by enhancing corporate image.Advertising has a great impact on children's and their parents' consumption behavior, while TV advertising is the main media that affects children's consumption emotion and behavior. According to the psychological characteristics of children, we need to focus on the image and vividness of advertising. In the advertisement creativity of children's goods, it is mainly to adopt the intuitionistic and image way, resort to the images rather than words, sensibility but not rationality. Through the lively image, the bright color, the pleasing sound, the attractive picture, the innocent interest and the exaggerated shape, the children feel the endless pleasure and the pleasure. We should use the means of change, mystery, novelty and grotesque to cater to children's curiosity. For example, it can make use of children's familiar cartoon stars as ads to create an absurd mood and strange plot. It can also make use of children's imitation and comparison psychology, and use children of the same age or their favorite accessories to induce consumption and render the pleasure and superiority of the product.

Brand strategy. The primacy effect plays a great role in the consumption psychology of children and their parents. Once they like a brand, trademark or commodity modeling, it is difficult to forget that in general and they will continue to be loyal to the same brand.

\section{Conclusion}

It brings the change of family structure based on the "universal two-child" policy,. Households will adjust their consumption structure and consumption behavior according to actual needs. Basic consumption expenditure such as clothing, food and housing is relatively stable, and quality and safety are concerned. The consumption type of households is changing towards the direction of development and enjoyment. Facing the new opportunities under the second child policy, the enterprise should analyze the characteristics of consumer demand, study the consumer psychology and behavior law, grasp the psychology of the consumer, predict the trend of its development and change, and adopt appropriate marketing strategy or marketing combination strategy. For second child family, all planned marketing activities are intended to be beneficial to children, to use the words or patterns that children can understand, to interact with children, and to meet the common desires and needs of children and parents. 


\section{Acknowledgement}

This paper is supported by Scientific research project of Guangdong University of Science \& Technology(GKY-2016KYYB-30);Guangdong Adult Education Association adult education research program(key projects)(Ycx161008).

\section{Reference}

[1] H.Y. Zhu:Research on consumption environment and consumption behavior of urban residents from the perspective of Chain Commerce . (MS.Fudan University, China2013),p.1-51.

[2]X.H.Wang,T.Wen. Research on the difference of consumption behavior and structure evolution between urban and rural residents[J] . Quantitative Economy Technology Economy Research, 2015(10),p.98-100.

[3] H.B.Yan:Consumer psychology . (Guangdong Higher Education Press, China2013),p.42-66.

[4] Yu D, Peng L. When does Inferring Reputation Probability Countervail Temptation in Cooperative Behaviors for the Prisoners' Dilemma Game? [J]. Chaos, Solitons \& Fractals, 2015, 78: 238-244. 